\title{
Is California's Aging Infrastructure the Principal Contributor to the Recent Trend of Power Outage?
}

\author{
Vivian Sultan, Ahmed Alzahrani, Hind Bitar and Norah Alharbi \\ Claremont Graduate University Center for Information Systems and Technology, Claremont, CA, USA
}

\begin{abstract}
The United States electric power infrastructure is in an urgent need of renovation. The recent incidents of major power outages in the city of Long Beach, Los Angeles, Simi Valley, San Diego, and San Francisco have drawn attention to the unreliability of California's electric power system. President Obama discusses America's aging power infrastructure and California Public Utilities Commission calls for a comprehensive review of the causes of the recent power outages. This report explores GIS (geographic information systems) and their aim to identify a correlation between the power plants age and the power outages in the state of California. Utilizing ArcMap OLS (ordinary least squares) modeling tool, data analysis shows no correlation between the power outages and the infrastructure age.
\end{abstract}

Key words: Component, power outages, electric power infrastructure, ArcMap, OLS, GIS, investigate power outage.

\section{Introduction \& Problem Definition}

Electrical power, within a short time, has become a necessity of modern life. Our work, healthcare, leisure, economy, and livelihood depend on the constant supply of electrical power. Even a temporary power outage can lead to relative chaos, financial setbacks, and possible loss of life. Our cities dangle on electricity and without the constant supply from the power grid, pandemonium would break loose. Power outages can be especially tragic when it comes to life-support systems in places like hospitals and nursing homes or systems in synchronization facilities such as in airports, train stations, and traffic control. According to Ref. [1], the economic cost of power interruptions to U.S. electricity consumers is $\$ 79$ billion annually in damages and lost economic activity. That is why we believe that it is important to know about the possible causes of power failure in order to better protect ourselves and our businesses from its devastating effects.

There are many reasons behind power failure that we are facing today. Among these reasons are severe

Corresponding author: Vivian Sultan, M.Sc., research field: energy informatics. weather, damage in electric transmission lines, shortage of circuits, and the aging of power grid infrastructure. When examining some of these reasons, the research team found that severe weather is the leading cause of power outages in the United States [2]. Another reason was the aging of the grid infrastructure. In 2008, the American Society of Civil Engineers gave America's power grid infrastructure an unsatisfactory grade [3]. They stated in a report that the power transmission system in the United States required immediate attention. Furthermore, the report mentioned that America's electric power grid is similar to those of third-world countries. According to the Electric Power Research Institute, transformers controlling power transmission need to be replaced as they have exceeded their expected lifespan considering the materials' original design [4]. All these facts have drawn our attention to investigate whether what has been said about the grid infrastructure is true or not. And if it is true, investing billions on renewing these plants is justified. Otherwise, we need to increase the grid's resilience by making it less vulnerable to weather-related outages and reducing the time it takes to restore power after an outage occurs. 
The research team employed GIS (geographic information systems) to investigate America's power concern and to answer this research question: "Is there a relationship between the increase in power outages incidents and the aging of the infrastructure?" The research team has chosen California as a research site because it represents the power outage issue of the US. Utility customers who were impacted by the associated damages of the recent power outages in the state of California [5], those who are in danger of future power outages, city officials, policy makers, and utility regulators are all looking for answers to the question we are trying to address. They are looking to understand the factors and events that led to the recent power outage incidents. If a positive correlation between the power outages and the aging of the infrastructure is identified, utility spending to maintain and improve power transmission and distribution systems can be easily justified.

\section{Literature Review}

According to Ref. [1], the economic cost of power interruptions to U.S. electricity is $\$ 79$ billion annually. Meanwhile, modern life requires a consistent supply of electric power [1]. After an extensive literature review, we only found scattered segments in this topic. The research team set out to do two steps. The first step is to research the reasons behind the recent power outages and whether the age of the power plants was one of them. The second step is to research America's aging grid infrastructure.

Despite the increase in the amount of power outages in the United States, we could not find a solid investigation about the reasons behind the increase of these outages and who is to blame. However, individual investigations about specific power outages around the country have been made. For instance, according to Ref. [6], when the Great Blackout of 2011 happened, it was found to be the largest power failure in California history and have managed to affect approximately 2.7 million customers.
According to the same report, the outages affected parts of Arizona, Southern California, Baja California, and Mexico [6]. After looking into this report and other similar ones that investigate individual power outages, we concluded that the main factors behind these outages were unpredictable weather, operations planning, unreliability of the grid, and situational awareness. Other causes of power outages include: operational failures, equipment malfunctions, circuit overloads, and vehicle accidents [2].

Moreover, according to Ref. [2], severe weather is the leading cause of power outages in the United States. "Between 2003 and 2012, an estimated 679 widespread power outages occurred due to severe weather" [2]. Likewise, the research found that the annual costs changed significantly and were greater due to major storms such as Hurricane Ike in 2008. Another finding is that the aging grid has made Americans more vulnerable to outages caused by severe weather. Additionally, "seventy percent of the grid's transmission lines and power transformers are now over 25 years old and the average age of power plants is over 30 years" [2]. Furthermore, the research forecasted that 58 percent of total outages witnessed since 2002 were caused by severe weather such as thunderstorms, hurricanes, and blizzards. Finally, "Data from the U.S. Energy Information Administration show that weather-related outages have increased significantly since 1992” [2].

The second step that the project team researched was America's aging grid infrastructure. According to Ref. [7], 70\% of transmission lines and transformers are at least 25 years old and $60 \%$ of circuit breakers are at least 30 years old. "Older lines and transformers are more susceptible to failure, and lines carry electricity less efficiently as they age” [7]. At the same time, much of infrastructure in the grid was designed in the 1950s, before the introduction of microprocessors, so utilities have had to adapt electromechanical systems to work with digital operations outside of their intended design. The paper 
also addressed several factors that interact with the age and restricted functionality of the grid to impede safe, reliable, and efficient operation. These factors are: severe weather, the physical layout of the transmission grid threats, the advent of new cyber, and the traditional measurement and monitoring approaches [7].

The next book that the project team examined is Ref. [8]. The book identified equipment age as the active factor of aging system and implied that it was the catalyst for utilities problems. "While equipment aging is an important factor, it is not the sole, and in many cases not even the primary factor at work in creating the service and cost problems that many utilities face" [8]. Moreover, the book described the characteristics of an aging infrastructure, and some of them are: (1) the majority of equipment in the area is more than 40 years old and (2) the area is plagued by above-average equipment failure rate [8].

\section{Data Selection and Acquisition}

\subsection{Infrastructure Data}

California Energy Almanac is the data source for the state infrastructure data. "The Energy Almanac was developed by the California Energy Commission to provide current and historical information all housed in one place, dozens of data and statistical pages" [9]. The project team calculates the age per Megawatt per city based on the following weighted average technique:

$$
\operatorname{Age}_{c}=\sum_{i=1}^{m}\left(T_{i} * \frac{W_{i}}{\sum_{i=1}^{m} W_{i_{i}}}\right)
$$

Age $_{c}=$ Age of power infrastructure in city "C"

$\mathrm{Ti}=$ Tenure of power plant " $\mathrm{i}$ "

$\mathrm{Wi}=$ Megawatt produced by power plant "i”

An excel model has been developed by the project team to calculate the age per Megawatt energy data as illustrated by the next example for the city of Anaheim. According to our data sources, there are two plants in City of Anaheim for which we show the Megawatt energy data and the plant online year as follows:

The age per Megawatt energy for the city of Anaheim can be calculated as shown below:

(1) Calculate the plant age by deducting the online year from the current year.

Plant "A" age $=2015-1990=25$

Plant “B” age $=2015-2011=4$

(2) Compute total Megawatt energy per city by adding the Megawatt energy of all plants in the city.

City of Anaheim total Megawatt energy = Plant "A" MW + Plant "B" MW = 46 + $100=146$

(3) Determine the plant contribution to the city total Megawatt energy by dividing the Plant Megawatt energy by the city total Megawatt energy (from step 2). Plant "A" contribution to the city total Megawatt energy $=46 / 146=31.51 \%$. Plant " $B$ " contribution to the city total Megawatt energy $=100 / 146=68.49 \%$

(4) Calculate the plant weighted age based on its contribution to the total Megawatt energy of the city by multiplying the result of step 3 (the plant contribution to the city total Megawatt energy) by the plant age (result of step 1).

Plant " $\mathrm{A}$ " weighted age $=31.51 \%$ x $25=7.88$

Plant "B" weighted age $=68.49 \%$ x $4=2.74$

(5) Determine the age per Megawatt energy for the city by adding the all plants' weighted age calculated in step 4. Age per Megawatt energy for the city of Anaheim = Plant "A" weighted age + Plant "B" weighted age $=7.88+2.74=10.62$.

To conclude, the model developed by the project team relied primarily on the power plants' years of operations data and employed a weighted average

Table 1 City of Anaheim plants in MW.

\begin{tabular}{llll}
\hline Plant & Online-MW & Online-Year & Plant-city \\
\hline Plant “A” & 46 & 1990 & ANAHEIM \\
Plant “B” & 100 & 2011 & ANAHEIM \\
\hline
\end{tabular}


calculation methodology to compute the cities' power infrastructure age within the State of California. The link to the California power plant data is http://www.energyalmanac.ca.gov/electricity/index.ht $\mathrm{ml}$. The excel sheet model is provided in the appendix section attached.

\subsection{Power Outage Data}

The project team found scattered data on power outages on the web. However, they are neither a consistent index nor in one file format. Southern California Edison (2015) reliability reports are the single source for the power outage data. Other companies' power outage data did not specify the locations where the outages happened. The project team transferred the power outage data from SCE cities' reliability reports (PDF files) to an Excel file. We relied on the SAIDI (system average interruption duration index) per city to demonstrate the amount of time the average customer was without power from 2011 to 2014 [10].

\section{System \& Methodology}

GIS has been effectively used in the utility industry to help meet a lot of objectives. There are two main goals for using GIS in the utility industry: "driving down costs and improving customer service” [11]. Merey adds that GIS application is widely used as advanced mapping tool for marketing, planning, as well as operational purposes.

Electric utilities have been provided GIS solutions in many aspects i.e. Electric distribution, power generation, and transmission services. For example, in order to build a transmission line, GIS would help "selecting suitable areas, finding the optimum path, creating the profile analysis, engineering design of towers and wires, surveying support, and estimating costs” [12]. Additionally, transmission line inspection is important and critical to keep the electric power flowing.

GIS can be a main resource of assistance for electronic inspection system. Southern Company is a large utility company that provides electronic inspection to five individual companies with different inspection requirements to every company. The company adopted the GIS by using ArcPad to gather data on field, processed them in TLIS and then collected them in one database combined with GIS information. As a result, "Inspection contractors and Southern Company personnel are able to more effectively and efficiently perform their inspections in the field and use this information to make the main set of equipment information more complete and reliable" [12]. GIS applications have also been utilized to control and forecast power outages. "We have been able to lower the duration of customer outages, improve crew response time, and reduce labor and overtime costs by $\$ 240,000 "$ said Chris Folta, Manager of Applications and Integration, Benton Public Utility District [13]. The project methodology can be divided into the following steps.

\subsection{Load Outages Data (SAIDI) of Each City along with the Age per MW Data to Web ArcGIS}

The Excel file of the data was geocoded and loaded to web ArcGIS. A map was created with two layers. The first layer showed the power infrastructure age (Age Per MW) per city. This layer was visualized by selecting a green circle symbol from web ArcGIS counts and amounts tool (Fig. 1). In addition, Age Per MW data was classified into four classes using the manual brakes option. The second layer showed the total duration of outages per city based on SAIDI value. A Heat Map was selected to visualize this layer in which blue color showed low SAIDI and light yellow color showed high SAIDI index (Fig. 2).

4.2 Utilize Kernel Density Estimation (KDE) tool to estimate the probability density of random variables

The web ArcGIS map layer was accessed from ArcMap 10.3 software in order to run various statistical tools. According to [14], KDE was the first 
tool employed to show the density of the outages across the map (Figure 3). A limitation of this tool is that it doesn't take into account the values of the entire dataset.

\subsection{Utilize Optimized hotspot analysis tool to identify} hot and cold spots

Optimized hotspot analysis tool is useful to identify statistically significant hot and cold spots of outages using the Getis-Ord Gi* statistic in SAIDI (Figure 4) [14]. The tool showed spots in cities such as La
Canada and Pasadena where SAIDI index were statistically significant.

\subsection{Employ OLS (Ordinary Least Square) Tool to} Identify the Relationship between Dependent and Independent Variables

OLS tool uses a statistical analysis technique to make modeling spatial to identify the relationship between two variables [14]. SAIDI and Age Per MW were the two variables inputs for the OLS tool (Fig. 5).

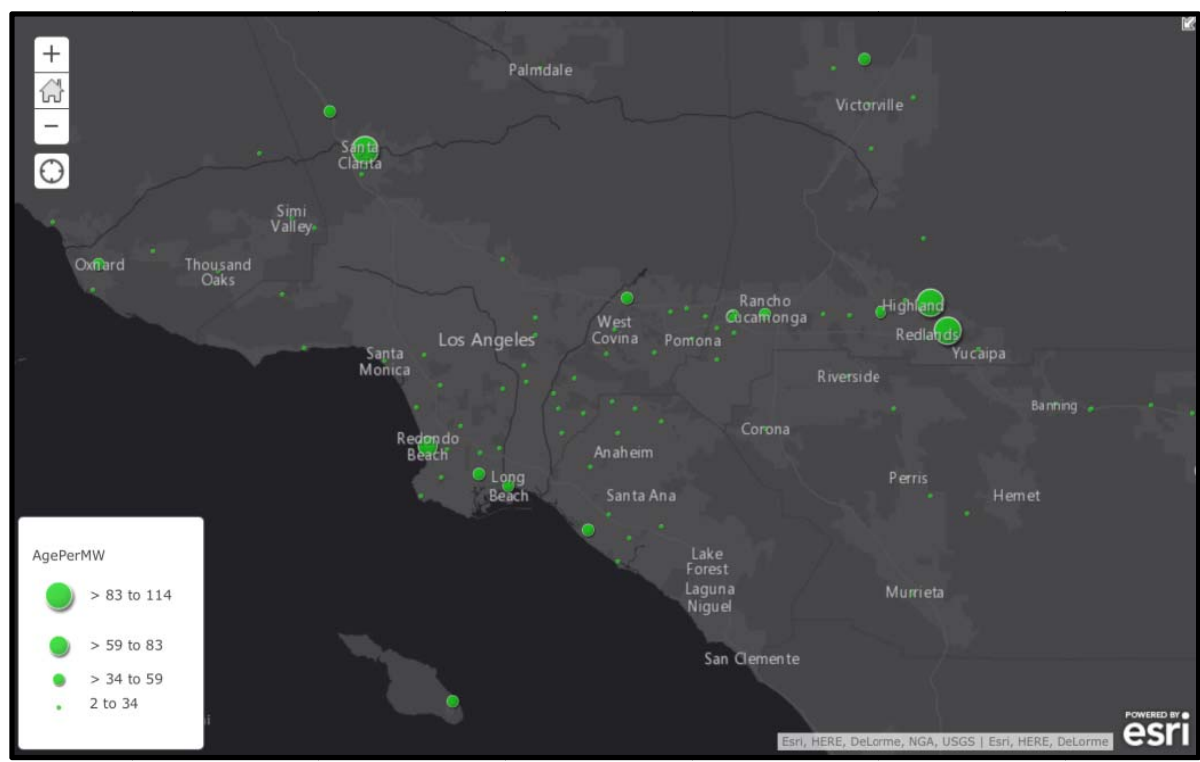

Fig. 1 Infrastructure age (Age Per MW) per city.

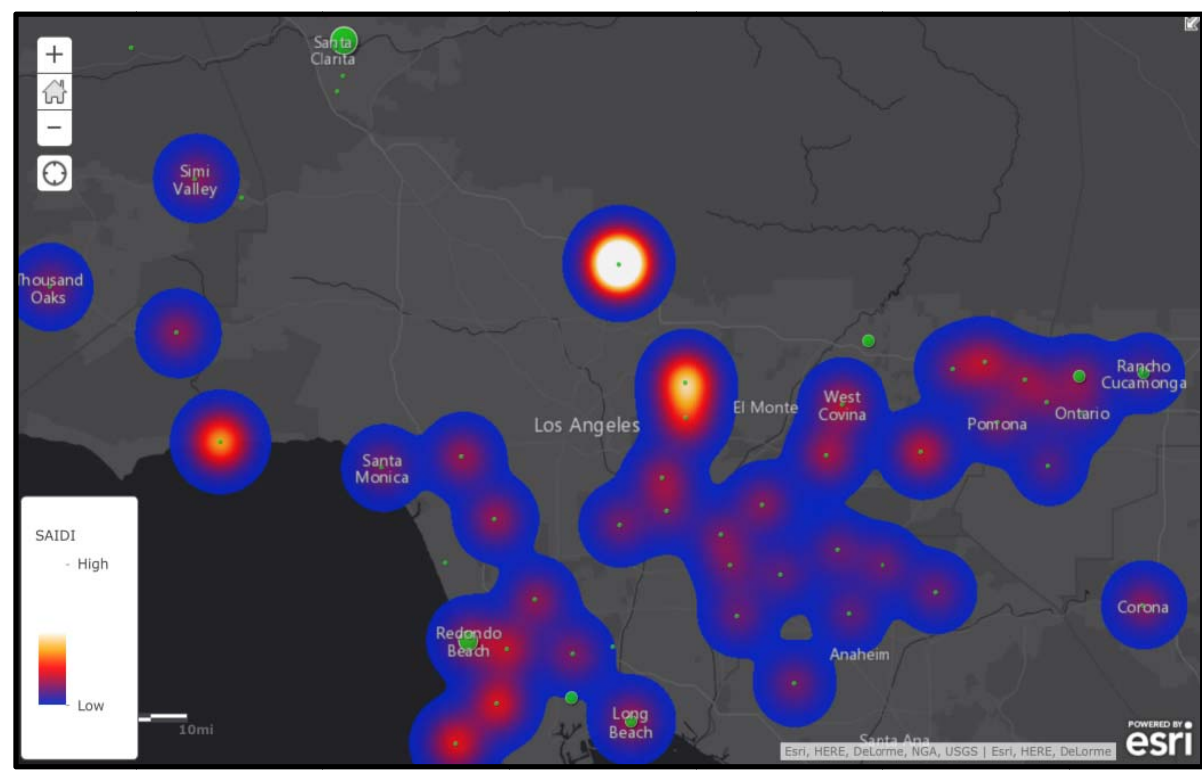

Fig. 2 The total duration of outages per city based on SAIDI value. 


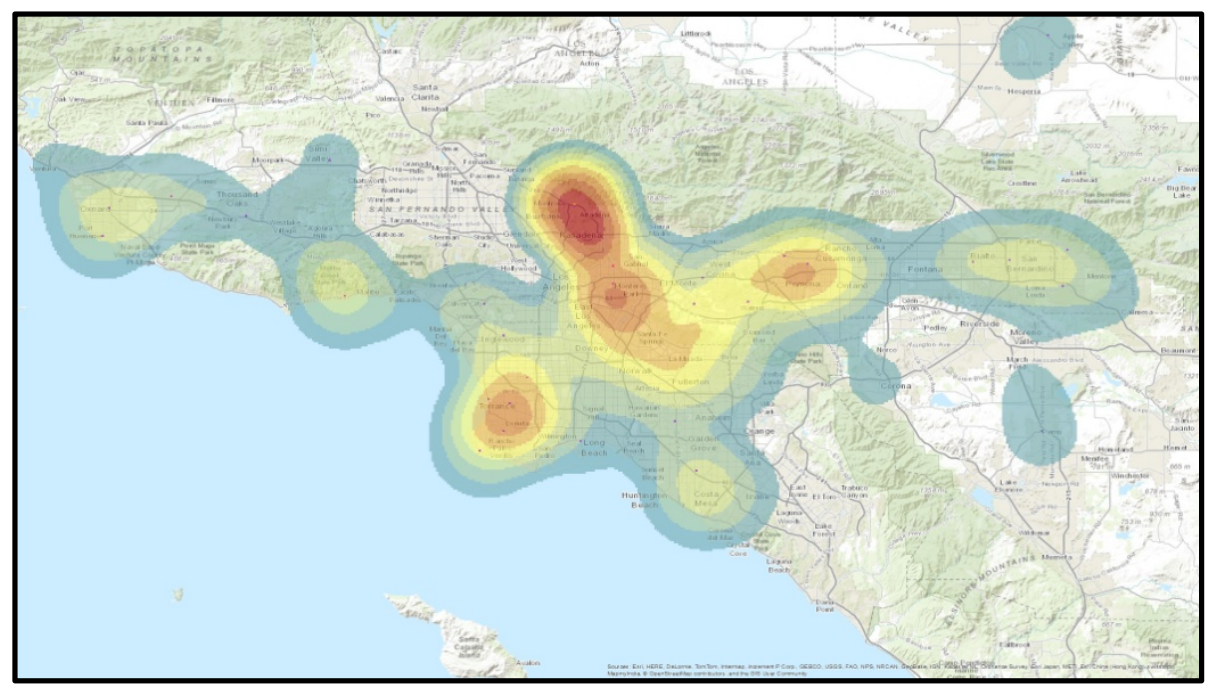

Fig. 3 KDE (kernel density estimation).

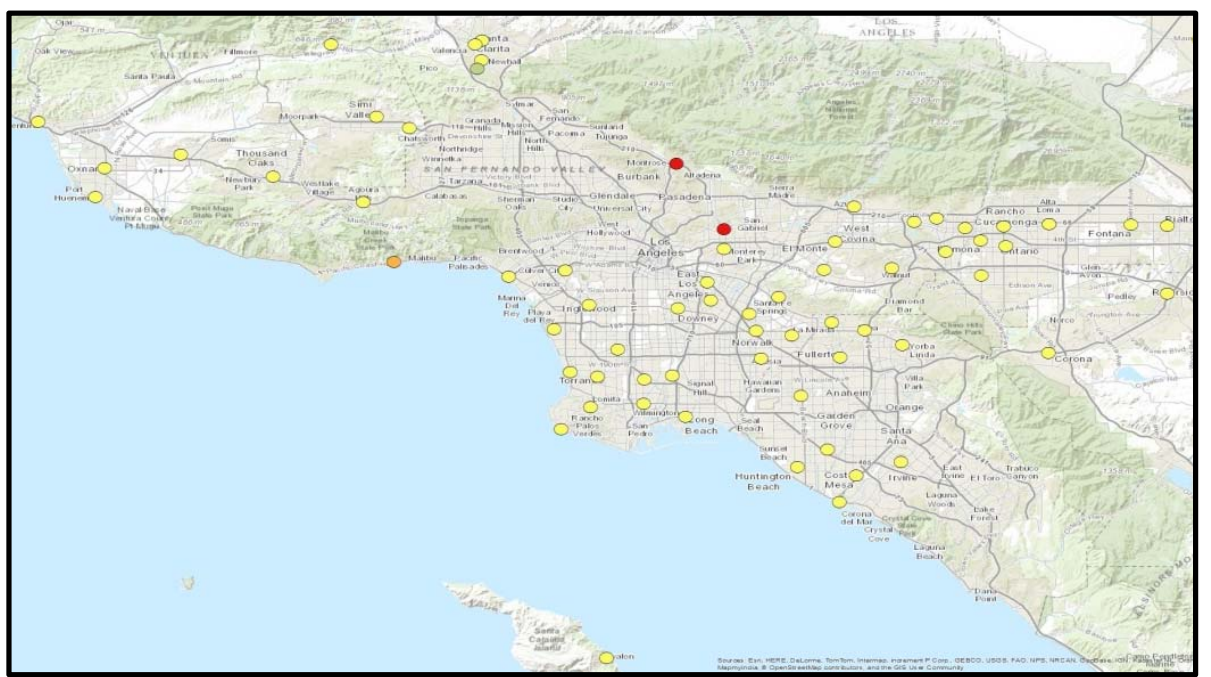

Fig. 4 Optimized hotspot analysis.

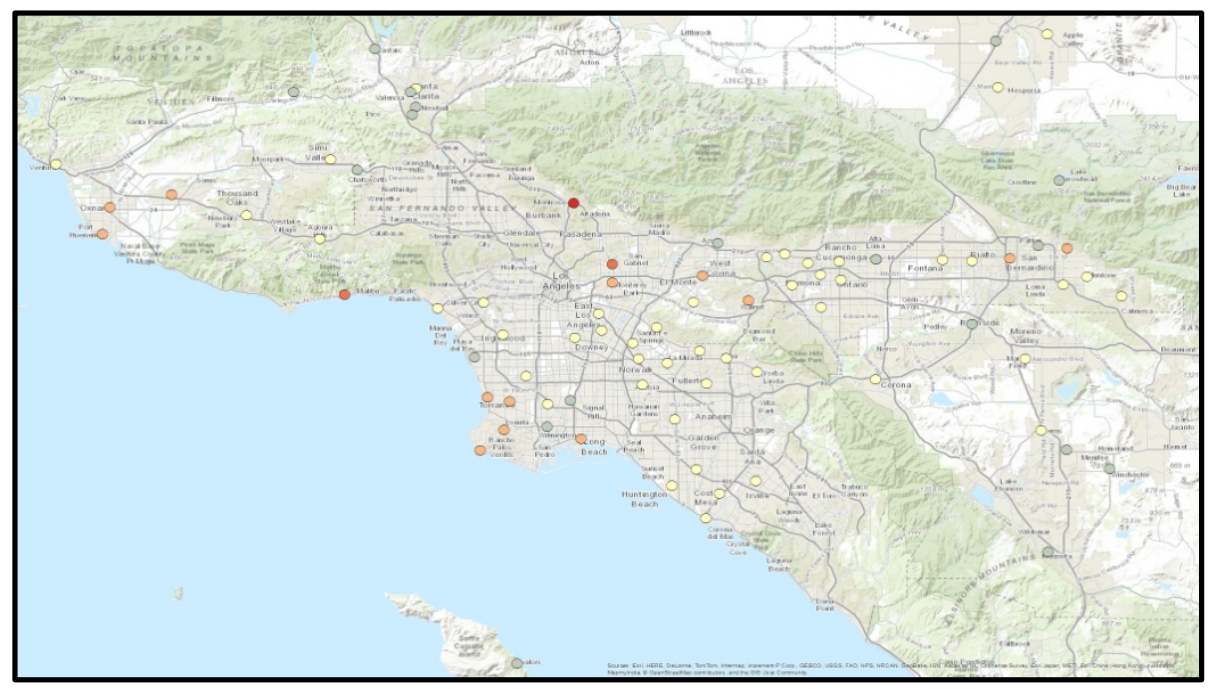

Fig. 5 Ordinary least square. 


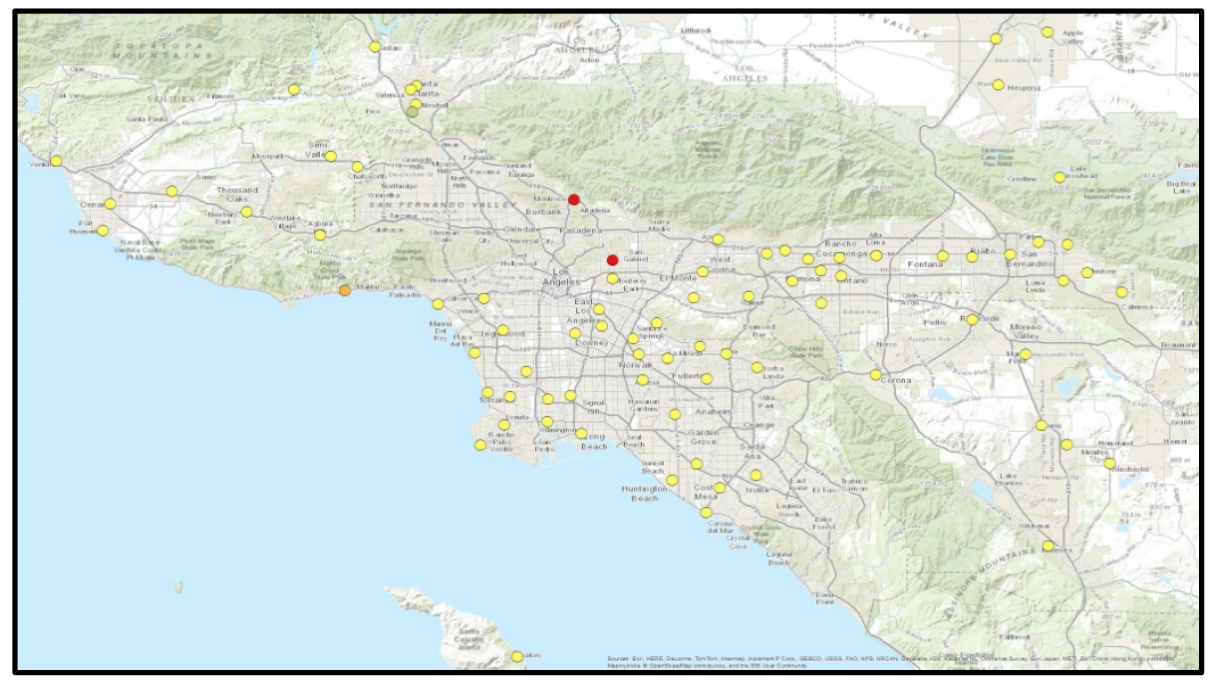

Fig. 6 The optimized hot spot analysis for AGE PER MW and SAIDI.

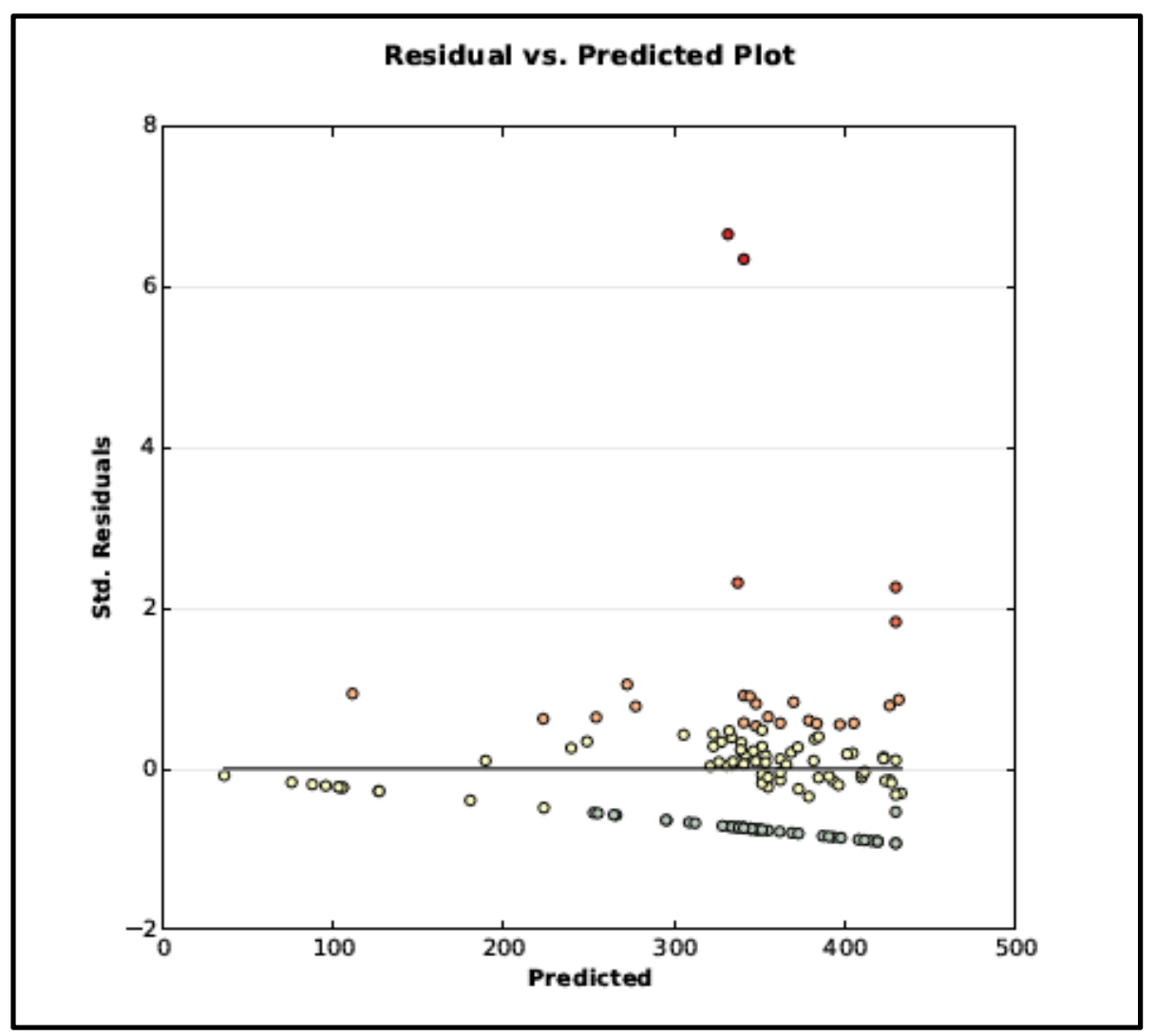

Fig. 7 The relation between explanatory (AGE PER MW) and dependent variable (SAIDI).

\section{Analysis and Finding}

In the analysis, the project team first used Optimized Hot Spot Analysis to generate a map of statistically noteworthy hot and cold spots using the Getis-Ord $\mathrm{Gi}^{*}$ statistic. This tool assessed the characteristics of the input feature class to produce optimal results [14]. We used SAIDI as an analysis field. The map indicated that there were two hot spots that appear in Pasadena and La Canada cities. However, the majority of spots were not either hot or cold, which means that there is no correlation between the infrastructure and the plant's power outages in the 
state of California (Fig. 6).

The second tool that the project team applied is OLS. This tool is a prediction model, which based on having dependent and explanatory variables. The explanatory variable in this study is Age Per MW data, and the dependent variable is the SAIDI index. The OLS report showed that there was no correlation between the dependent and the explanatory variables. The age of the infrastructure is not the main cause of the power outages that occurred in the selected sample in this study. The R-squared in OLS model assess how close the data are to the fitted regression line. Hence, the higher the R-squared is, the more correlation will be Ref. [14]. In this model, the R-squared is 0.032292, which indicated that the model explained almost none of the variability of the response data around its mean. As the result, there is no relationship between the age of the infrastructure and outages that happened from 2011 to 2014 as shown in Fig. 7.

Nevertheless, as shown in the Optimized Hot Spot Analysis and the OLS model (Figs. 4 and 5), there was a couple of hotspots in Pasadena and La Canada cities. After investigating the possible causes that led to the big outages that occurred in 2011, the project team found that the main reason was the winds, which affected many cities in San Bernardino and Los Angeles areas. In November 30, 2011, a huge windstorm cut off the power lines, which caused a huge outage that affected nearly 481,000 businesses and residences [15]. That is why those hot spots appeared in our model.

\section{Conclusion}

This research presents a GIS model based on the spatial correlation of the power infrastructure age and the power outage incidents in the last four years in California. The analysis indicates no correlation between the two variables based on the OLS model. One limitation was the lack of more precise data about the power outage because the SAIDI index only gave us the average duration of power outage. Future research should include power outage data by electric circuit instead of the SAIDI index. Also, additional variables such as the electricity usage by circuit and weather data can be further added to enhance the proposed model.

\section{References}

[1] LaCommare, K., and Eto, J. 2004. Understanding the Cost of Power Interruptions to U.S. Electricity Consumers. Berkeley, CA: Lawrence Berkeley National Laboratory.

[2] President's Council of Economic Advisers and the U.S. Department of Energy's Office of Electricity Delivery and Energy Reliability, with assistance from the White House Office of Science and Technology 2013. Economic Benefits of Increasing Electric Grid Resilience to Weather Outages. Retrieved November 19, 2015, from http://energy.gov/sites/prod/files/2013/08/f2/Grid Resiliency Report_FINAL.pdf.

[3] Infrastructure fact sheet. 2009. Retrieved October 7, 2015, from

http://www.infrastructurereportcard.org/2009/sites/defaul t/files/RC2009_rail.pdf.

[4] Stone, D. 2011. It's the Electric Grid, Stupid. Retrieved October 5, 2015, from http://www.thedailybeast.com/articles/2011/09/09/majorpower-outage-shows-weakness-of-aging-electric-infrastru cture.html.

[5] Senator Ricardo Lara Calls for Independent Investigation of Long Beach Power Outages. (n.d.). Retrieved October 7, 2015, from https://lbpost.com/news/2000006684-senator-ricardo-lara -calls-for-independent-investigation-of-long-beach-power -outages\%20.

[6] Federal Energy Regulatory Commission, \& North American Electric Reliability Corporation. 2012. Arizona-Southern California Outages on September 8, 2011: Causes and Recommendations from http://www.ferc.gov/legal/staff-reports/04-27-2012-ferc-n erc-report.pdf.

[7] The National Governors Association. 2014. Governors' Guide to Modernizing the Electric Power Grid. http://www.nga.org/files/live/sites/NGA/files/pdf/2014/1 403GovernorsGuideModernizingElectricPowerGrid.pdf.

[8] Willis, H., and Schrieber, R. 2013. Aging Power Delivery Infrastructures (2nd ed.). Boca Raton: CRC Press/Taylor \& Francis.

[9] California Electricity Data, Facts, \& Statistics. (n.d.). Retrieved October 7, 2015, from http://www.energyalmanac.ca.gov/electricity/index.html. 
[10] Southern California Edison. 2015. Retrieved November 1, 2015 , from https://www.sce.com/wps/portal/home/outage-center/relia bility-reports/!ut/p/b1/rVLBcoIwEP0Ve-CIWcBg6C2tLc I4tkprhQsDGJEWCGKU8veNjpfOVK3T7im78_bN25e HAjRHQRntsjQSGS-jfN8HZug6A6rZPd0Ba4qB3k8J1p 4ftRE2JMCXADhRFA77GrHp0PHAIaNZH5w725vMn mcwtDT0hgIUJKWoxAr5m4SFCS8FK0XISgWObwX4 VkQp6ySyYbUCNcuzKM7yTLSdmlW8Fps9TZVkC-Sz 3lInslSyMGO1h5eJauHIVEmCddDMPsYmO8o-o-vC2Q fZEmLZ8DB0n8CxXyYGOMYExh6lBoB5BJxz5pI3Lgr SnMeHb_BpGRskRUHNlqxmdXdby_FKiGpzq4ACTdN 0U87TnHUTXijw08qKbwSaf0ciXzrRP3nqCCPvSmvPE w7gvwn1qwndX4Q6e1-vAyqjuY_gp7TtL9msiteCGK36 MSWtke-KIhyP1SgmbUNvvgAMAlE3/dl4/d5/L2dBISE vZ0FBIS9nQSEh/\#/accordionGrp1-5/accordionGrp1-1/a ccordionGrp1-2/accordionGrp1-3/accordionGrp1-4/accor dionGrp1-6/accordionGrp1-7/accordionGrp1-8/accordion Grp1-9/accordionGrp1-10/accordionGrp1-11/accordionG rp1-12.

[11] GIS in the utilities (n.d.). Retrieved October 10, 2015.
From

http://www.geos.ed.ac.uk/ gisteac/gis_book_abridged/fil es/ch57.pdf.

[12] GIS Solutions for Power Generation and Transmission Services gis sols for power generation (n.d.). Retrieved $\begin{array}{llll}\text { October } & 10, & 2015 . & \text { From }\end{array}$ http://www.esri.com/library/brochures/pdfs/gis-sols-for-p ower-generation.pdf.

[13] A Real-Time Network Picture, Benton Public Utility Esri (n.d.). Retrieved October 9, 2015. From https://www.esri.com/library/casestudies/benton-public-u tility-district.pdf.

[14] Arc GIS for desktop (n.d.). Retrieved November 18, 2015. from https://desktop.arcgis.com/en/desktop/latest/tools/spatialstatistics-toolbox/optimized-hot-spot-analysis.htm.

[15] 13 of the Largest Power Outages in History -and What They Tell Us about the 2003 Northeast Blackout - The Equation. (n.d.). Retrieved October 7, 2015. From http://blog.ucsusa.org/2003-northeast-blackout-and-13-of -the-largest-power-outages-in-history-199. 